\title{
The Problems and Countermeasures of Organizational Power in Universities
}

\author{
Xiaoqian Zhang \\ Henan Radio \& Television University \\ Email: zhangxiaoqian@open.ha.cn
}

Keywords: academic power, academic organization, administrative power, administrative organization

\begin{abstract}
There are two basic forms of academic power and executive power within universities. At present, the institutions of higher education have problems, for instance, the administrative organizations are complex, academic organizations are fragmented, and the supervision mechanism is far from enough. Thus, it is an important step to change the setting and management form of administration, improve the structure of academic institutions and weaken the social service function, establish the reasonable and effective mechanism of academic.
\end{abstract}

\section{Introduction}

There are two basic forms of power of academic power and executive power within universities [1], which are determined by the function of the university to create knowledge, impart knowledge, inherit civilization and promote social progress. On the one hand, as a large organization, universities need administrative management and administrative power, on the other hand, academic activities, is one of the important content, colleges and universities to carry out academic activities of the main body, organizations or individuals shall be given appropriate autonomy and control, these rights belong to the category of academic power. The academic power and administrative power is internal and universities are the two sets of decision system, having positive influence of mutual restrict, mutual complement, there are conflicting, resist the negative impact of each other. How to use these two kinds of power, give full play to the function of academic power are not administrative power is out of control, according to the school's mission and goals like two kinds of power system to achieve high coordination, his each form finding, can all is, and get a good situation, different tactics is one of the present research focus in the field of higher education management.

\subsection{Existing problems and situations}

The administrative and academic institutions in universities are the carriers of administrative power and academic power, and the existence and exercise of power are restricted by institution and management system. The structure of internal administrative organization of colleges and universities is large, which involves all aspects of administrative affairs management, which generally shows the top-down management of management. Ideal type of dissecting for anyone in the organization must follow the common rules and system, dissecting the application helps to establish a rational relationship in colleges and universities, in order to safeguard the organization operation, so as to achieve maximum benefit. The limitations of university functions and bureaucracy require that institutions of universities should be set up and the distribution of power must go beyond the bureaucracy. With the refined social division of labor, in the top-down management system mode, one institutional and organizational structure is more and more large, the power and responsibility is clear but of power and responsibility division, accrual seepage conditions.

\subsection{Weak academic authority}

Academic management and administrative management are two basic management methods of university organizations. Of higher education in China with reference to the government on the 
organizational system, with the administrative management model and management of academic institutions, to form the management mode dominated by administrative constraints, sidelined by administrative power, academic power lead to lost university academic standard. Academic organization directly lead to the lack of academic power and administrative power to compete in the process of status gradually reduce function, also gradually weakened, experts and scholars are needed by master certain administrative power for academic initiative, involved in the administrative areas of academic staff too much.

\subsection{There is academic hegemony}

"Academic freedom will be affected by the threat from the government and the academic organization itself, and the organization once formed a kind of specific and solidifying point of view, and can suppress other organizations or individuals in the rise and development of the different point of view." [2] The academic authority embodies the respect and obedience of the academic community to learning, not the absolute and solidification of academic authority, nor should it be degenerated into academic hegemony. Academic hegemony has serious damage to the existence of the academic activities of purity, dampened the enthusiasm of young scholars research, from a long-term point of view, to the cultivation of talents, knowledge innovation has a huge backlash.

\subsection{Imperfect legislation}

Academic freedom and university autonomy need to accept government administration and legal supervision. Both administrative and academic activities should play a role in the law-clarified scope and field, and establish a management operation mechanism for managing schools according to law. [3] To perfect the relevant laws and regulations of the higher education is the basis of the standard management of colleges and universities and the safeguard, but from the perspective of China's existing laws and regulations also has many loopholes, this will give the management of specific work to bring inconvenience. At the national level, relevant laws and regulations should be developed as soon as possible to standardize and ensure the legalization of administrative activities and academic activities. Given the speed of the process of our legal steps far couldn't catch up with the development of colleges and universities, colleges and universities should develop a because of the articles of association of the university condition management standardization of administrative and academic affairs in the university, clear punishment measures to crack down on not conducive to the development of the school activities.

\section{Countermeasures and Suggestions}

The higher school is a formal and normative academic organization, and its grass-roots academic organizations should devote themselves to the creation and inheritance of knowledge and pursue the management goals of freedom, autonomy and self-government [3]. To improve the basic academic organization can help the innovation of scientific research technology. Therefore, it is necessary to set up diversified grass-roots academic organizations in the future, to give the basic academic organizations and professors the reasonable power to innovate the basic academic organizations. To promote the institutionalization and standardization of academic power in colleges and universities is the state in the future.

\subsection{Weaken the functions of social services}

The largest manifestation of university administration is to assume excessive social functions.[4]In recent years, with the enlargement of the scale of higher education, expanding social function target, lead to internal organization structure of colleges and universities has become increasingly complex, in addition to normal teaching, scientific research and other academic affairs, student management, organizational guarantee, logistics and other non-academic matters of responsibility is more and more big, the task is getting heavier and heavier, the colleges and universities to improve the internal organization efficiency and the management effectiveness. Non-administrative and non-academic institutions occupy the public resources and funds of schools, 
and even bring serious administrative burden to universities. Colleges and universities should gradually combine these institutions with social service functions or to separate them from the establishment of school institutions, so that the university's responsibilities are more pure.

\subsection{Establish a reasonable and effective academic mechanism}

Academic system including external academic system and internal academic system, external academic system is to point to by the legislative branch or academic institutions (academic committee, etc.) set to restraint, standard, navigate the academic individuals and organizations of various kinds of laws, regulations and rules, including the legal system of academic, academic evaluation system and rewards and punishment system. Establish reasonable academic assessment and supervision mechanism and external guarantee of normal operation of academic activities, improve the professional ethics accomplishment, administrators and scholars was regulating the behavior of their own academic is the inherent requirement of academic activities.

\subsection{Establish a reasonable and effective supervision mechanism for academic evaluation}

To establish academic norms, peer review and external evaluation must be carried out. Firstly, due to the particularity of knowledge products, the results produced by scholars in universities need some time or test methods to show the effect. The knowledge that has lag sex is tested in the market is not to see any value, so only the colleague is likely to make judgement. Second, external evaluation must be introduced for procedural justice, prevention of internal manipulation and exclusion.

With the rapid progress of society and the expansion of university scale, the construction of administrative management system and mechanism in universities is far behind the development of universities themselves. On the one hand, it is often a problem to make a system, but it is too late to mend. On the other hand, there is a corresponding management system and supervision mechanism, but there is no specific department management, which can't be implemented. The document spirit has become a dead letter. The most urgent thing is to establish the administrative authority and the academic authority as soon as possible to supervise the management and supervision mechanism, find the blind area of management, make the administrative affairs and academic affairs become transparent and institutionalized.

\section{Conclusions}

Administration of colleges and universities is that colleges and universities are not able to act according to the standards of establishing modern universities in the process of their development, but in accordance with the administrative system of the structure and operation mode to construct and run, the essence of which is refers to the administrative power in the academic affairs, arise out of the bureaucratic, utilitarian, tools, provincial and other unhealthy practices, make university lost should have a pure and noble temperament and character, also deviated from the nature and mission of the university. Power relations in itself is not bad, must be completely abandoned, is the key subject for the improvement of moral standards, regulatory system and the improvement of the organization structure, to achieve a variety of power and coordinate with each other, finally reach the goal realization.

\section{References}

[1] B. L. Zhong The relationship between academic power and administrative power of modern university and its coordination [J]. China Higher Education, 2005(19):3-5.

[2] Y. Z. Zhang Professor's Academic Authority and Realistic Predicament. Journal of National Academy of Education Administration, 2010(4):39-43

[3] X. M. Xu The theory of university [J]. Social Sciences in China, 2010(06):36-43. 